\title{
An Evaluation of Potential Inhibition of CYP3A4/5 and CYP2C9 Enzymatic Activity by Boswellia serrata Extract
}

\author{
Amy L. Roe, ${ }^{1}$ Rachel Wilcox, ${ }^{2}$ Jason M. Price, ${ }^{1}$ Lijuan Li,, Hong Dai,, Kimberly M. Freeman, ${ }^{3}$ Weslyn W. Friley, ${ }^{3}$ \\ Ashley G. Herman, ${ }^{3}$ Christopher B. Black, ${ }^{3}$ Kenneth R. Brouwer, ${ }^{3}$ and Jonathan P. Jackson ${ }^{3}$
}

\begin{abstract}
Introduction: As the use of dietary supplements increases, botanical-drug interaction (BDI) potentials should be evaluated. Boswellia serrata extract (BSE) is traditionally used as an anti-inflammatory supplement. In the scientific literature, BSE has been shown to reduce the activity $(55 \%$ to $\geq 65 \%)$ across major CYP450 enzymes, including CYP3A4/5 and CYP2C9, using baculovirus-infected insect cells. These reported results, contrasted with a seemingly history of safe use of BSE, led us to question the relevance of the results using pooled human liver microsomes (PHLM), when compared to a more physiologically relevant model such as primary human hepatocytes.
\end{abstract}

Methods: This study compared PHLM and sandwich-cultured human hepatocytes (SCHH) by evaluating BSE potential inhibitory effects on CYP3A4/5 and CYP2C9 enzymatic activity.

Results: In SCHH, inhibition of CYP3A4/5 by BSE was observed resulting in an $\mathrm{IC}_{50}=17.4 \mu \mathrm{g} / \mathrm{mL}$ with maximum inhibition effect of $>70 \%$ at $75 \mu \mathrm{g} / \mathrm{mL}$ versus $\mathrm{IC}_{50}=1.4 \mu \mathrm{g} / \mathrm{mL}$ with a maximum inhibition effect of $98 \%$ at $50 \mu \mathrm{g} / \mathrm{mL}$ in PHLM. IC 50 values for CYP2C9 inhibition by BSE were $>75 \mu \mathrm{g} / \mathrm{mL}$ with a maximum inhibition effect of $<30 \%$ versus $11 \mu \mathrm{g} / \mathrm{mL}$ with a maximum inhibition effect of $84 \%$ at $50 \mu \mathrm{g} / \mathrm{mL}$ using SCHH and PHLM, respectively.

Discussion and Conclusions: Potent CYP3A4/5 and CYP2C9 inhibition observed for BSE in microsomal systems was not observed in SCHH. SCHH are particularly useful for studying complex mixtures such as botanicals. Although our data would suggest that BDI with BSE is low for most drugs, narrow therapeutic drugs such as warfarin should still be used with caution when combined with BSE.

Keywords: Boswellia serrata, botanical-drug interactions, Burseraceae, CYP2C9, CYP3A4/5, sandwich-cultured human hepatocytes

\section{Introduction}

$\boldsymbol{B}$ OSWELLIA SERRATA (Indian Frankincense) belongs to the Burseraceae family and is native to India, Northern Africa, and the Middle East. The oleogum resin of $B$. serrata possesses anti-inflammatory properties and has been used in a number of inflammatory diseases, including asthma, osteoarthritis, rheumatoid arthritis, ulcerative colitis, and Crohn's disease. $^{1,2}$ The phytochemical constituents associated with anti-inflammatory properties of $B$. serrata are believed to be various pentacyclic triterpenes. ${ }^{2}$ As many as 12 or more different boswellic acids have been identified across various Boswellia species, with structures of the most prevalent for B. serrata shown in Table 1. It is known that boswellic acids are absorbed from oral administration since circulating levels of several of these constituents have been documented in human plasma (Table 1). ${ }^{1-9}$ To date, much focus has been on the activity of 11-keto- $\beta$-boswellic acid (KBA) and acetyl-11keto- $\beta$-boswellic acid; however, $\beta$-boswellic acid (BBA) levels have been shown to be 100 -fold higher in human plasma. ${ }^{1}$

Over $50 \%$ of adults in the United States use various types of supplements and recent reports indicate herbal supplement

\footnotetext{
${ }^{1}$ The Procter \& Gamble Company, Cincinnati, Ohio.

${ }^{2}$ Cedarville University School of Pharmacy, Cedarville, Ohio.

${ }^{3}$ ADME-Tox Division, BioIVT, Durham, North Carolina.
}

(c) Amy L. Roe et al. 2019; Published by Mary Ann Liebert, Inc. This Open Access article is distributed under the terms of the Creative Commons License (http://creativecommons.org/licenses/by/4.0), which permits unrestricted use, distribution, and reproduction in any medium, provided the original work is properly cited. 
Table 1. Structures and Human Plasma Concentrations of the Major Boswellic Acids Reported from Various Human Clinical Studies

\begin{tabular}{|c|c|c|c|}
\hline Boswellic acid & Structure & Reported human plasma concentration $(\mu M)$ & References \\
\hline $\mathrm{BBA}$ & & $\begin{array}{c}0.412 \text { (Fasted) } \\
2.453 \text { (Fed) } \\
7.471 \\
10.1 \\
6.35\end{array}$ & $\begin{array}{l}4 \\
6 \\
7 \\
8\end{array}$ \\
\hline KBA & & $\begin{array}{c}2.72 \\
1.9 \\
0.178 \text { (Fasted) } \\
0.482 \text { (Fed) } \\
0.333 \text { (Fasted) } \\
0.436 \text { (Fed) } \\
0.138 \\
0.34 \\
0.091 \\
0.33\end{array}$ & $\begin{array}{l}3 \\
1 \\
2 \\
5 \\
\\
6 \\
7 \\
9 \\
8\end{array}$ \\
\hline Acetyl-KBA & & $\begin{array}{c}0.0117 \text { (Fasted) } \\
0.0562 \text { (Fed) } \\
0.0591 \text { (Fasted) } \\
0.0640 \text { (Fed) } \\
0.0302 \\
0.1 \\
0.04\end{array}$ & $\begin{array}{l}2 \\
5 \\
\\
6 \\
7 \\
8\end{array}$ \\
\hline$\alpha$-Boswellic acid & & $\begin{array}{l}0.692(\text { Fed }) \\
3.551 \\
3.5\end{array}$ & $\begin{array}{l}4 \\
6 \\
7\end{array}$ \\
\hline Acetyl- $\alpha$-boswellic acid & & $\begin{array}{c}0.238(\mathrm{Fed}) \\
0.894 \\
4.0\end{array}$ & $\begin{array}{l}4 \\
6 \\
7\end{array}$ \\
\hline Acetyl- $\beta$-boswellic acid & & $\begin{array}{l}1.724 \\
2.4 \\
4.90\end{array}$ & $\begin{array}{l}6 \\
7 \\
8\end{array}$ \\
\hline
\end{tabular}

BBA, $\beta$-boswellic acid; KBA, 11-keto- $\beta$-boswellic acid.

sales continue to grow each year. ${ }^{10,11} B$. serrata extract (BSE)-containing products have gained popularity with sales skyrocketing to a $674 \%$ increase, as reported in 2014 based on the American Botanical Council's annual report on herbal supplement sales in the United States. ${ }^{12}$ Retail sales have continued to increase in subsequent years to 14.6 million in 2017, corresponding to an average annual growth of roughly $210 \% .{ }^{11}$ Furthermore, B. serrata contin- ues to move up the list of 40 top-selling herbal supplements in the United States, and is currently positioned at number 19. ${ }^{11}$ A Search of the U.S. National Institutes of Health (NIH) Dietary Supplement Label Database (DSLD) for $B$. serrata resulted in 460 products found containing $B$. serrata in the label. ${ }^{13}$ The majority of BSE-containing products in commerce are marketed toward providing joint health $(46 \%)$, flexibility (18\%), and 
anti-inflammation benefits $(6 \%)$. Due to a high prevalence of age-related inflammatory disorders, older adults may seek out anti-inflammatory herbal supplements such as BSE. ${ }^{14}$ In fact, older adults ( $>65$ years) are the top consumers of herbal supplements in general and almost two-thirds of this population also use at least three or more prescription drugs. ${ }^{15-17}$ Thus, this population may be particularly at risk for botanical-drug interactions (BDI).

A previous study assessed the CYP450 inhibitory potential of six boswellic acid constituents in BSE using a mixture of CYP450 enzymes from baculovirus-infected insect cells. ${ }^{18}$ The authors reported that out of the six active boswellic acids, BBA and KBA were among the most potent inhibitors across the majority of CYP450 enzymes studied (CYP1A2/ $2 \mathrm{C} 8 / 2 \mathrm{C} 9 / 2 \mathrm{C} 19 / 2 \mathrm{D} 6)$. We chose to further investigate the CYP450 inhibitory potential of BSE in both pooled human liver microsomes (PHLM) and a more physiologically relevant model, sandwich-cultured human hepatocytes ( $\mathrm{SCHH})$. Our study utilized SCHH because this model provides a better physiologic representation of in vivo liver function due to the presence of fully functional uptake and efflux transporters and metabolic enzymes (i.e., hepatic clearance pathways), and key regulatory pathways (e.g., CAR/PXR). ${ }^{19-21}$ Furthermore, our laboratory has successfully used SCHH to study interaction potential with complex botanical mixtures. ${ }^{22}$

We chose to focus on the effects of BSE on CYP2C9 and CYP3A4/5 specifically, since these isoforms were previously shown to be the most potently inhibited by BSE. More importantly, CYP2C9 is the primary CYP isoform involved in the clearance of the nonsteroidal anti-inflammatory drug (NSAID), ibuprofen. ${ }^{23}$ The CYP2C9 enzyme is responsible for formation of the primary metabolite of ibuprofen, 3hydroxy ibuprofen (Fig. 1). Although NSAIDs like ibuprofen are effective pain and inflammatory relievers, the gastric and cardiovascular side effects associated with chronic use may limit their utility, particularly in the elderly. ${ }^{1,14}$ Thus, as part of the overall safety assessment of BSE, we considered the potential for concomitant use of BSE with NSAIDs in individuals seeking alternative sources of adjunctive therapy to treat chronic inflammatory diseases such as osteoarthritis. The potential for BSE to inhibit CYP3A4/5 was also included in our studies since this isoform metabolizes $>50 \%$ of all prescription medicines, and it is also involved in ibuprofen clearance, although at higher concentrations. ${ }^{23}$

In addition, we wanted to compare data generated from using more simplistic in vitro screening models, such as PHLM, to more sophisticated SCHH for assessing BDI potential. Liver microsomes lack cellular processes, including uptake and efflux transporters, the full range of metabolizing enzymes, and the regulatory machinery that controls these processes. These functional gaps likely decrease the accuracy of microsomes in translating in vitro results to in vivo predictions.

\section{Materials and Methods}

\section{Chemicals}

The primary analytical standards KBA (96.9\% adjusted purity) and BBA (98.1\% adjusted purity) were purchased from ChromaDex (Irvine, CA). The internal standard oleanolic acid- $d_{3}(97 \%$ chemical purity and $98 \%$ isotopic purity) was purchased from Toronto Research Chemicals (North York, Ontario). Methanol (Honeywell LC/MS Grade, $\geq 99.9 \%$ ), water (Honeywell LC/MS Grade), and isopropanol (EMD, $\geq 99.9 \%$ ) were purchased from VWR (Radnor, PA). Ammonium formate $(\geq 99.0 \%)$ and 2-butanol (anhydrous, $99.5 \%$ ) were purchased from Sigma-Aldrich Co. LLC (St. Louis, MO).

For the PHLM studies, diclofenac, 4'hydroxydiclofenac, sulfaphenazole, midazolam, ketoconazole, $\beta$-NADP, glucose6-phosphate, and glucose-6-phosphate dehydrogenase were purchased from Sigma-Aldrich Co. LLC; 1'-1'-hydroxymidazolam

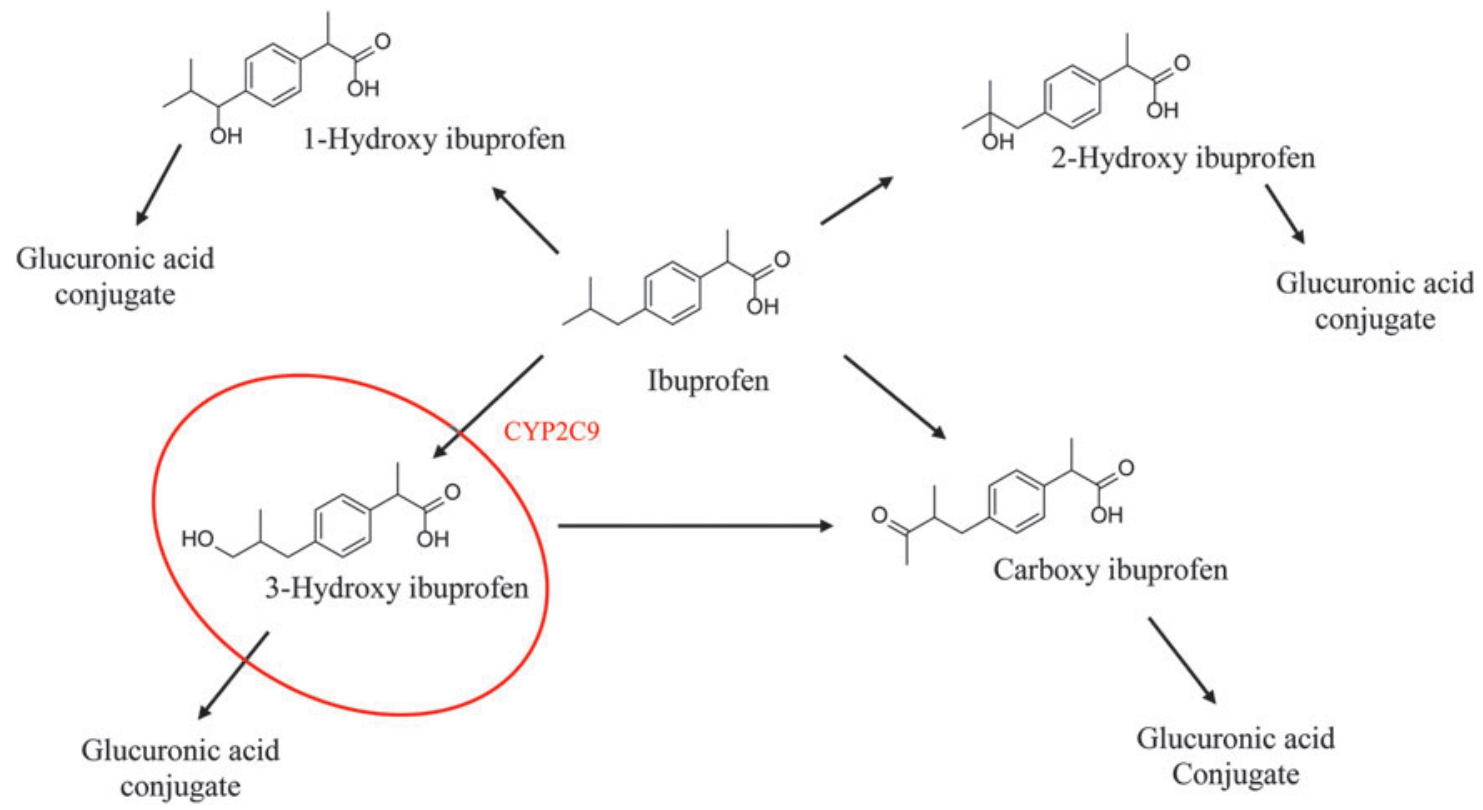

FIG. 1. The metabolic pathway for ibuprofen, including the CYP2C9-mediated metabolite formation of 3-hydroxy ibuprofen. ${ }^{22}$ 
was purchased from Cerilliant (Round Rock, TX) for use in PHLM studies. Potassium phosphate buffer, $\mathrm{MgCl}_{2}$, and EDTA were purchased from Sigma-Aldrich Co. LLC.

For SCHH studies, tamoxifen, ketoconazole, fluconazole, midazolam, DMSO, ammonium acetate, formic acid, and methanol were purchased from Sigma-Aldrich Co. LLC. BSA Fraction V was purchased from Calbiochem (Billerica, MA), HBSS was purchased from Thermo Fisher (Waltham, MA), and Matrigel ${ }^{\circledR}$ was purchased from BD Biosciences (San Jose, CA). QualGro ${ }^{\mathrm{TM}}$ Seeding Medium and QualGro Hepatocyte Culture Medium were obtained internally as they are proprietary culture medium from ADME-Tox Division of BioIVT, formerly Qualyst Transporter Solutions, Durham, NC.

\section{Plant materials and extractions}

B. serrata resin (oleogum resin; Part\#:00030155-018; Lot\#:00030155-018; CDXA\#:CDXA-08-0285), a 100\% methanol extract dried to a creamy yellowish powder, was used in both PHLM and SCHH studies, was purchased from Chromadex (Irvine, CA) and contained a total boswellic acids content of $42.9 \%$ by weight, based on Certificate of Analysis. According to supplier's Certificate of Analysis, $80 \mathrm{mg}$ of oleogum resin was sonicated for 15 minutes with $100 \mathrm{~mL}$ of $100 \%$ acetonitrile and filtered through a nylon syringe filter before HPLC UV-VIS analysis. The following is the individual boswellic acid content characterized by HPLC UV-VIS (DAD) detector and reported on the Certificate of Analysis: (as $100 \mathrm{mg} / \mathrm{g}$ ) $\alpha$-boswellic acid (8.17\%), BBA (19.3\%), 3-acetyl- $\alpha$-boswellic acid (1.84\%), 3-acetyl- $\beta$ boswellic acid $(7.19 \%)$, KBA $(4.66 \%)$, and 3 -acetyl-KBA $(1.70 \%)$.

\section{Test article preparation}

For the initial PHLM studies, a DMSO stock solution of $5 \mathrm{mg} / \mathrm{mL} \mathrm{B}$. serrata oleogum resin or dried $100 \%$ methanol extract (BSE) powder was prepared for $\mathrm{IC}_{50}$ evaluations. The stock solution was prepared by dissolving dried BSE powder directly into $100 \%$ DMSO. From this stock solution, stock solutions of $0.01-50 \mu \mathrm{g} / \mathrm{mL}$ were prepared by dilution using $100 \%$ DMSO.

For the SCHH studies, a $237 \mathrm{mg} / \mathrm{mL}$ stock solution was prepared by dissolving dried BSE powder directly into $100 \%$ DMSO. Stock solutions of $7.5,23.7$, and $75 \mathrm{mg} / \mathrm{mL}$ BSE were prepared from dilutions of the $273 \mathrm{mg} / \mathrm{mL}$ stock solution using 100\% DMSO. All BSE solutions were stored at $4^{\circ} \mathrm{C}$. On days of exposure, BSE stock solutions were freshly diluted $1000 \times$ directly into cell culture medium for cytotoxicity evaluations or Hank's balanced salt solution (HBSS) buffer in the absence or presence of $4 \%$ bovine serum albumin (BSA), fraction V for CYP450 enzyme inhibition, and BSE intracellular concentration (ICC) studies. The final organic solvent in all incubations was $\leq 0.1 \%$.

\section{In vitro PHLM studies}

Human liver microsomes from nontransplantable, donated livers were prepared and characterized by Xenotech, LLC (Kansas City, KS), as outlined by Pearce et al. ${ }^{24}$ and Parkinson et al. ${ }^{25}$ The initial in vitro metabolic systems used in these studies were PHLM ( $N=16$ donors). This work was conducted in its entirety at Xenotech, LLC.

\section{$I C_{50}$ determinations: direct CYP450 inhibition evaluation of BSE in PHLM}

To examine its ability to act as a direct inhibitor of CYP2C9 and CYP3A4/5, BSE (at concentrations ranging from 0.01 to $50 \mu \mathrm{g} / \mathrm{mL}$ ) was incubated with marker substrates (diclofenac and midazolam, respectively), and PHLM. Incubations were conducted in duplicate at $\sim 37^{\circ} \mathrm{C}$ in $200 \mu \mathrm{L}$ incubation mixtures (target $\mathrm{pH} 7.4$ ) containing water, potassium phosphate buffer $(50 \mathrm{mM}), \mathrm{MgCl}_{2}(3 \mathrm{mM})$, EDTA $(1 \mathrm{mM})$, and NADPH-generating system (always the mixture of the following: NADP [1 mM], glucose-6-phosphate [5 mM], and glucose-6-phosphate dehydrogenase [1 U/mL]), marker substrates (diclofenac [6 $\mu \mathrm{M}]$ or midazolam $[4 \mu \mathrm{M}]$ ), and test article or positive control inhibitor, including sulfaphenazole ( $2 \mathrm{M}$, direct), ketoconazole $(0.5 \mu \mathrm{M}$, direct), tienilic acid $(1 \mu \mathrm{M}$; metabolism dependent), or troleandomycin (7.5 $\mu \mathrm{M}$, metabolism dependent). Marker substrate reactions were initiated by the addition of an aliquot of an NADPH-generating system and terminated by the addition of acetonitrile and internal standard $4^{\prime}$-hydroxydiclofenac- $d_{4}$ or $1^{\prime}$-hydroxymidazolam- $\mathrm{d}_{4}$ after $\sim 5$ minutes.

To examine time-dependent inhibition of CYP2C9 and CYP3A4/5, BSE (at the same concentrations used to evaluate direct inhibition) was preincubated at $37^{\circ} \mathrm{C} \pm 1^{\circ} \mathrm{C}$, in duplicate, with PHLM with and without an NADPH-generating system for $\sim 30$ minutes. Following the 30 -minute preincubation period, marker substrate was added, and the incubations were continued to measure residual CYP enzyme activity as described previously.

\section{Sandwich-cultured transporter certified ${ }^{\mathrm{TM}}$ human hepatocytes}

The SCHH studies were conducted by BioIVT. Freshly isolated hepatocytes for cytotoxicity assessments were plated on 24-well cell culture plates and overlaid by Triangle Research Laboratories (TRL, Durham, NC) and shipped to BioIVT. After receipt of SCHH, BioIVT rinsed and fed with QualGro human hepatocyte culture medium, a proprietary culture medium. Due to the unpredictable availability of fresh hepatocytes, cryopreserved hepatocytes were purchased from TRL and utilized for all subsequent SCHH assessments. Cryopreserved hepatocytes were thawed following manufacturer's instructions. Cryopreserved hepatocytes were subsequently suspended in BioIVT proprietary hepatocyte seeding medium (QualGro seeding medium) at a density of 0.8 million viable cells $/ \mathrm{mL}$ onto BioCoat ${ }^{\circledR}$ 24-well cell culture plates.

Following plating, cells were attached for 2-4 hours, rinsed, and fed with warm $\left(37^{\circ} \mathrm{C}\right)$ seeding medium. Eighteen to 24 hours later, cells were fed and overlaid with QualGro human hepatocyte culture medium supplemented with extracellular matrix, Matrigel ${ }^{\circledR}(0.25 \mathrm{mg} / \mathrm{mL})$. Cells were maintained in QualGro hepatocyte culture medium, refreshing media every 24 hours until consumed in studies.

\section{Evaluation of BSE cytotoxicity potential in $\mathrm{SCHH}$}

On day 6 of cultures, SCHH were exposed to 7.5, 23.7, and $75 \mu \mathrm{g} / \mathrm{mL}$ of BSE for 4 or 24 hours. This range of BSE 
concentrations was chosen to encompass concentrations tested in previous in vitro studies as well as levels of boswellic acids in marketed products where known. Lactate dehydrogenase (LDH) and adenosine triphosphate (ATP) analysis were preformed to evaluate the cytotoxic potential of BSE in SCHH. Leakage of LDH was measured using the CytoTox-ONE ${ }^{\mathrm{TM}}$ Assay Kit from Promega (Madison, WI), according to the manufacturer's instructions. Fluorescence was recorded using a SpectraMax Gemini XS microplate reader. Cellular content of ATP was determined using the CellTiter-Glo ${ }^{\circledR}$ Assay Kit from Promega, according to the manufacturer's instructions. Luminescence was recorded using a SpectraMax Gemini XS microplate reader.

\section{$I C_{50}$ determinations: direct CYP450 inhibition evaluation of BSE in SCHH}

Cells were cultured in QualGro medium until day 7 of culture, when spent culture medium was aspirated and replaced with HBSS incubation solution with or without 4\% BSA. The inclusion of BSA served two purposes" (1) to increase aqueous solubility of BSE constituents and (2) to increase physiological relevance of the study design, since hepatocytes in vivo are exposed to xenobiotics in the presence of protein.

Incubation solutions were added directly to the $\mathrm{SCHH}$ containing P450 marker substrates, midazolam $(5 \mu \mathrm{M})$ for CYP3A4/5 or ibuprofen $(50 \mu \mathrm{M})$ for CYP2C9, and test article at various concentrations or a positive control inhibitor for a total incubation volume of $0.5 \mathrm{~mL}$. Positive control inhibitors included CYP3A4/5 selective inhibitor ketoconazole $(0.05$ and $0.25 \mu \mathrm{M})$ or CYP2C9 selective inhibitor fluconazole (5 and $100 \mu \mathrm{M}$ ) in situ incubations in triplicate were performed in cell culture incubators $\left(37^{\circ} \mathrm{C} ; 5 \% \mathrm{CO}_{2}\right.$; and $100 \%$ humidity) shaking at $120 \mathrm{rpm}$ for 20 or $30 \mathrm{~min}-$ utes, respectively. Following the incubation period, incubation solutions were removed from hepatocyte cultures and stored at $-80^{\circ} \mathrm{C}$ until processed for bioanalysis.

Sample preparation for in situ IC50 determinations. In situ incubations were analyzed for the detection of CYP450mediated metabolite formation of 1'-hydroxymidazolam from midazolam and 3-hydroxyibuprofen from ibuprofen. Briefly, a volume of $300 \mu \mathrm{L}$ of internal standard solution (methanol containing $25 \mathrm{nM}$ triazolam and $d_{3}$-ibuprofen) and a volume of $100 \mu \mathrm{L}$ of in situ incubation solutions were added to a protein precipitation plate (Millipore MDRPNP4) stacked on a 96deep-well block. The plate was shaken for 1-2 minutes before centrifugation for collection of the filtered supernatant. The sample filtrate was evaporated to dryness and the samples were reconstituted in $200 \mu \mathrm{L}$ sample diluent, 40/60 methanol/10 mM ammonium acetate, and mixed for at least 20 minutes on a plate shaker.

The reconstituted samples were transferred to a Millipore $0.45 \mu \mathrm{m}$ filter plate (Millipore MSHVN45) and filtered into a Costar 3957 plate by centrifugation and sealed with a silicone capmat before LC-MS/MS analysis. Calibration standards and quality control samples were prepared in duplicate for all analytes by spiking blank matrix (HBSS or HBSS plus 4\% BSA) with a known concentration of test compound for a final calibration range spanning from 1.00 to $500 \mathrm{nM}$ (HBSS) or 1.00-5000 nM (HBSS plus 4\% BSA).
Liquid chromatography-mass spectrometry/mass spectrometry analysis of in situ IC50 incubation samples. Liquid chromatography-mass spectrometry/mass spectrometry (LCMS/MS) measurements were performed using an HPLC system (Shimadzu) with LC-10ADvp pumps, CTC-PAL autosampler (Leap Technologies), and CTO-10Avp oven (Shimadzu). Thermo Scientific Hypersil Gold C18 column $(100 \times 1.0 \mathrm{~mm}$, $3 \mu \mathrm{m}$ ) was used. This system used two mobile phases: $10 \%$ methanol with $0.25 \mathrm{mM}$ ammonium acetate $(\mathrm{A})$ and $80 \%$ methanol with $0.25 \mathrm{mM}$ ammonium acetate $(\mathrm{B})$ at a flow rate of $50 \mu \mathrm{L} / \mathrm{min}$ with a linear gradient. Injection volume was $3 \mu \mathrm{L}$ with a run time of 10 minutes and column temperature set at $35^{\circ} \mathrm{C}$. MS analysis was performed using Applied Biosystems API-3000 instrumentation operated in electrospray ionization mode.

\section{ICC of phytochemical constituents}

On day 7 of culture, the $\mathrm{SCHH}$ were exposed to BSE $(0.75,2.37,7.59,23.7$, and $75 \mu \mathrm{g} / \mathrm{mL})$ in the presence of $4 \%$ BSA for 0.5 hours to determine the ICC of KBA and BBA in hepatocytes cells using B-CLEAR ${ }^{\circledR}$ technology. Following 30 minutes of exposure, the assay buffer was removed and the hepatocytes were washed with HBSS. Immediately following rinses, the tight junctions of treated SCHH were modulated using B-CLEAR technology (BioIVT) as previously described. ${ }^{20-22,26-28}$

The ICC of each analyte was calculated by dividing the mass of analyte in the hepatocytes (cellular accumulation) by the hepatocyte intracellular fluid volume of $7.69 \mu \mathrm{L} / \mathrm{mg}$ protein for hepatocytes as previously described. ${ }^{29}$ All mass values were generated from triplicate wells and are represented by the calculated mean and standard deviation from these biological replicates.

Preparation of standards and neat quality control samples. Separate standard and QC stock solutions of KBA, $\mathrm{BBA}$, and oleanolic acid- $d_{3}$ were prepared in methanol at $1.00 \mathrm{mg} / \mathrm{mL}$ and stored at $\sim 4^{\circ} \mathrm{C}$. Neat standards covering a concentration range of $0.25-1000 \mathrm{ng} / \mathrm{mL}$ were prepared on the day of analysis by adding $0.400 \mathrm{~mL}$ of the appropriate combined standard solution (various concentrations in 70/30 methanol/water) to an HPLC vial along with $0.020 \mathrm{~mL}$ of oleanolic acid- $d_{3}$ working internal standard solution $(160 \mu \mathrm{g} / \mathrm{mL}$ in methanol). Neat QC samples were prepared at concentrations of $2.00,75.0$, and $750 \mathrm{ng} / \mathrm{mL}$ in the same manner as the standards.

Preparation of matrix quality control samples. Matrix quality control samples $(2.5$ and $250 \mathrm{ng} / \mathrm{mL})$ were prepared by spiking $0.0125 \mathrm{~mL}$ of the appropriate combined KBA and BBA solution $(10.0$ or $0.100 \mu \mathrm{g} / \mathrm{mL}$ in methanol) into wells of the B-Clear ${ }^{\circledR}$ 24-well Analytical Blank Plate (BioIVT) and allowing the solvent to air dry. Oleanolic acid- $d_{3}$ working internal standard solution was added $(0.025 \mathrm{~mL})$ and the solvent allowed to air dry. Diluent $(0.500 \mathrm{~mL}$ of $70 / 30$ methanol/water) was added to each well, the plate was shaken on an orbital shaker at $300 \mathrm{mot} / \mathrm{min}$ for $20 \mathrm{~min}-$ utes, and the solution was transferred to an HPLC vial. Samples were centrifuged (Beckman Coulter Allegra X-15R) at $\sim 930 \mathrm{rcf}$ for 20 minutes at ambient temperature and a 
portion of the clear supernatant was transferred to an HPLC vial for LC/MS/MS analysis.

Preparation of cell lysate samples. The sample plate was thawed unassisted at room temperature. Oleanolic acid- $d_{3}$ working internal standard solution was added $(0.025 \mathrm{~mL})$ and the solvent was allowed to dry. Diluent $(0.500 \mathrm{~mL}$ of $70 / 30$ methanol/water) was added to each well and the samples prepared as described above for matrix quality control samples.

HPLC-MS/MS conditions. HPLC separation was performed on a Shimadzu HPLC system (LC20AD pumps and CBM-20A system controller) with a CTC HTS-PAL autosampler and a Waters Atlantis dC18 column $(2.1 \times 100 \mathrm{~mm}$, $3 \mu \mathrm{m})$. The mobile phase consisted of $6.4 \mathrm{mM}$ ammonium formate in water (A) and $6.4 \mathrm{mM}$ ammonium formate in $98 / 2$ methanol/water (B) at a flow rate of $0.25 \mathrm{~mL} / \mathrm{min}$ and a linear gradient from $60 \%$ B to $95 \%$ B over a period of 1 minute followed by a second linear gradient from $95 \%$ B to $97 \%$ over 6 minutes, a step to $100 \% \mathrm{~B}$ with an isocratic hold for 2 minutes. The total analysis time was 12 minutes, including a reequilibration step. The sample injection volume was $15 \mu \mathrm{L}$.

The HPLC effluent is interfaced to an Sciex Triple Quad 6500 mass spectrometer equipped with an IonDrive Turbo $\mathrm{V}$ source and TurboIonSpray probe operated in negative electrospray ionization mode. Global source and selected reaction monitoring (SRM) parameters were optimized to obtain the highest sensitivity for the boswellic acids. The SRM transitions $\mathrm{m} / \mathrm{z}, 455.2>377.3 \mathrm{~m} / \mathrm{z}, 469.1>391.3$, and $\mathrm{m} / \mathrm{z} 458>412$ were monitored sequentially for detection of BBA, KBA and oleanolic acid- $d_{3}$, respectively, with 100 msecond dwell times. In all cases, the precursor ions were deprotonated molecules.

Calibration curves were constructed by plotting the peak area ratios (BBA/oleanolic acid- $d_{3}$ and KBA/oleanolic acid$d_{3}$ ) for standards versus concentration and fitting the data to a quadratic curve with $1 / x^{2}$ fit weighting. Concentrations of boswellic acids in samples were determined by interpolation from the best fit line. Peak integration and calibration curve regression were performed within the Analyst 1.6.2 software package.

\section{$I_{50}$ determination calculations}

For IC50 determinations in PHLM, data were processed with a custom software program (DI IC I0 $_{50}$ LCMS Template version 2.1.2) for the computer program Microsoft Excel 2000 (Microsoft Corp.). When inhibition of CYP enzyme activity was observed during the $\mathrm{IC}_{50}$ determination experiments, the data were processed for the determination of $\mathrm{IC}_{50}$ values by nonlinear regression with XLfit3 (Version 3.0.5; ID Business Solutions Ltd.). This software utilizes the Levenberg-Marquardt algorithm to perform nonlinear regression fitting of the data.

$$
\text { Fit }=\text { background }+\frac{(\text { range }- \text { background })}{\left(1+\left(\frac{x}{\mathrm{I} \mathrm{C}_{50}}\right)^{\text {slope }}\right)} \text {. }
$$

For $\mathrm{IC}_{50}$ determinations in $\mathrm{SCHH}$, percentage of remaining enzymatic activity was determined, compared to the ac- tivity of vehicle controls, using the equation below. All percent (\%) remaining values were generated from triplicate wells and are represented by the calculated mean and standard deviation from these biological replicates

$\%$ remaining activity $=\frac{\text { mean metabolite formed }}{\text { sample }}$ mean metabolite formed $_{\text {solvent control }}$.

If $\geq 50 \%$ inhibition was observed, $\mathrm{IC}_{50}$ values were estimated by nonlinear regression analysis. Nonlinear regression $\left(Y=\right.$ bottom $+($ top - bottom $) /\left(1+10^{\wedge}((\operatorname{LogIC} 50-X) \cdot\right.$ HillSlope))) of percent remaining activity versus BSA concentration (Log) was performed using GraphPad Prism Software Version 7.0 (La Jolla, CA) to estimate the concentration reducing enzyme activity by $50 \%$ (e.g., $\mathrm{IC}_{50}$ ). Linear regression was utilized to estimate $\mathrm{IC}_{50}$ parameters of positive control inhibitors.

\section{Statistical analyses}

All calculations were performed using Microsoft Excel, 2010. Statistical significance of LDH leakage and ATP content results was evaluated using a two-way ANOVA followed by a Dunnett's multiple comparison test.

\section{Results}

\section{$I C_{50}$ determination of BSE in PHLM}

The inhibitory effects of BSE $(0.01-50 \mu \mathrm{g} / \mathrm{mL})$ on CYP2C9 and CYP3A4/5 were evaluated using PHLM. Direct inhibition of CYP2C9 and CYP3A4/5 was observed in PHLM incubated with BSE, with estimated $\mathrm{IC}_{50}$ values of 11 and $1.4 \mu \mathrm{g} / \mathrm{mL}$, respectively (Table 2). The maximum inhibition observed in PHLM was $84 \%$ and $98 \%$ at $50 \mu \mathrm{g} / \mathrm{mL}$ for CYP2C9 and CYP3A4/5, respectively. Similar IC $_{50}$ values were obtained in PHLM preincubated with BSE in the presence and absence of NADPH before evaluation of enzyme activity (Table 2). The lack of a potency shift of $\geq 2$-fold (left shift) in the $\mathrm{IC}_{50}$ values following a preincubation suggested that BSE was likely not a time-dependent inhibitor through either an NADPH-dependent (e.g., CYP450 mediated) or NADPHindependent process.

\section{Cytotoxicity assessments of BSE in SCHH}

To avoid confounding inhibition results with effects of cytotoxicity, initial studies were conducted to assess BSE cytotoxic potential in SCHH. LDH leakage and ATP content were monitored following 4 and 24 hours after BSE treatment $(7.5,23.7$, and $75 \mu \mathrm{g} / \mathrm{mL})$. Significant LDH leakage of $85.6 \%$ of total LDH content was observed in SCHH following 24 hours of treatment with the positive control, tamoxifen $(50 \mu \mathrm{M}$; Fig. 2A). ATP content was also significantly reduced to $<2.1 \%$ of solvent control in SCHH treated with tamoxifen $(50 \mu \mathrm{M})$ for 24 hours (Fig. 2B). These results demonstrated that $\mathrm{SCHH}$ were sensitive to a known metabolism-dependent toxicant. No statistically significant increases in LDH leakage were observed in SCHH treated for 4 or 24 hours with any concentration of BSE assessed (Fig. 2A). ATP content of SCHH treated with increasing concentrations of BSE showed only minor reduction in ATP depletion (e.g., $\leq 21.3 \%$ ) across the concentrations and exposure periods assessed (Fig. 2B). Overall, these results 
Table 2. In Vitro Evaluation of Boswellia SERRata Extract as an Inhibitor of CYP2C9 and CYP3A4/5 in PoOled Human Liver Microsomes

\begin{tabular}{|c|c|c|c|c|c|c|c|c|}
\hline \multirow[b]{2}{*}{ Enzyme } & \multirow[b]{2}{*}{$\begin{array}{l}\text { Enzyme } \\
\text { reaction }\end{array}$} & \multirow[b]{2}{*}{$\begin{array}{c}\text { Test } \\
\text { system }\end{array}$} & \multicolumn{2}{|c|}{$\begin{array}{l}\text { Direct } \\
\text { inhibition }\end{array}$} & \multicolumn{2}{|c|}{$\begin{array}{l}\text { Time-dependent } \\
\text { inhibition }\end{array}$} & \multicolumn{2}{|c|}{$\begin{array}{c}\text { Metabolism-dependent } \\
\text { inhibition }\end{array}$} \\
\hline & & & $\begin{array}{c}I C_{50} \\
(\mu g / m L)^{\mathrm{b}}\end{array}$ & $\begin{array}{c}\text { Inhibition } \\
\text { observed at } \\
50 \mu \mathrm{g} / \mathrm{mL} \\
(\%)^{\mathrm{c}}\end{array}$ & $\begin{array}{c}I C_{50} \\
(\mu g / m L)^{\mathrm{b}}\end{array}$ & $\begin{array}{c}\text { Inhibition } \\
\text { observed at } \\
50 \mu \mathrm{g} / \mathrm{mL} \\
(\%)^{\mathrm{c}}\end{array}$ & $\begin{array}{c}I C_{50} \\
(\mu g / m L)^{\mathrm{b}}\end{array}$ & $\begin{array}{c}\text { Inhibition } \\
\text { observed at } \\
50 \mu \mathrm{g} / \mathrm{mL} \\
(\%)^{\mathrm{c}}\end{array}$ \\
\hline CYP2C9 & Diclofenac $4^{\prime}$-hydroxylation & PHLM & 11 & 84 & 9.8 & 87 & 12 & 87 \\
\hline CYP3A4/5 & Midazolam 1'-hydroxylation & PHLM & 1.4 & 98 & 1.4 & 99 & 1.8 & 100 \\
\hline
\end{tabular}

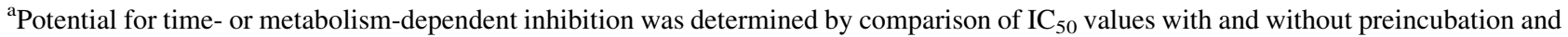
with and without NADPH-generating system present in the preincubation, by comparison of the observed inhibition (\%) for all preincubation conditions and by visual inspection of the $\mathrm{IC}_{50}$ plots.

${ }^{\mathrm{b}}$ Average data (i.e., percent of control activity) obtained from duplicate samples for each test article concentration were used to calculate $\mathrm{IC}_{50}$ values.

"Inhibition observed $(\%)$ is calculated with the following formula (results are rounded to two significant figures): inhibition observed $(\%)=100 \%$ - percent solvent control.

BSE, Boswellia serrata extract; PHLM, pooled human liver microsomes.

suggested that BSE has low cytotoxic potential in $\mathrm{SCHH}$ at the concentrations tested up to 24 hours of exposure.

\section{$I C_{50}$ determinations of BSE in $\mathrm{SCHH}$}

Less than $30 \%$ inhibition of CYP2C9 was observed in $\mathrm{SCHH}$ over the tested range of BSE (up to $75 \mu \mathrm{g} / \mathrm{mL}$ ) and with or without $4 \%$ BSA added to the incubations (Fig. 3), and thus estimated $\mathrm{IC}_{50}>75 \mu \mathrm{g} / \mathrm{mL}$. In contrast, the positive control inhibitor (fluconazole) decreased CYP2C9-mediated formation of 3-hydroxyibuprofen in an exposure-dependent manner in the absence or presence of $4 \%$ BSA (Table 3), indicating system conditions were sufficient to detect inhibition of CYP2C9 enzyme activity.

The positive control inhibitor, ketoconazole, inhibited CYP3A4-/5-mediated formation of hydroxymidazolam in an exposure-dependent manner in the absence and presence of $4 \%$ BSA (Table 3), suggesting system conditions were also sufficient to detect inhibition of CYP3A4 enzyme activity. Exposure-related decreases in CYP3A4/5 enzyme activity were observed in the absence and presence of 4\% BSA. However, CYP3A4-/5-mediated formation of 1 -hydroxymidazolam only decreased greater than $50 \%$ of solvent control by BSE in the presence of $4 \%$ BSA, providing an estimated $\mathrm{IC}_{50}$ value of $17.4 \mu \mathrm{g} / \mathrm{mL}$ (Fig. 4). Maximum CYP3A4/5 inhibition of $>70 \%$ was observed in $\mathrm{SCHH}$ following exposure to $75 \mu \mathrm{g} / \mathrm{mL} \mathrm{BSE}$ in the presence of $4 \%$ BSA.

\section{ICC determination of BSE in SCHH}

To further understand the concentrations of BSE phytochemical constituents at the enzyme level, we measured $\mathrm{ICC}$ of $\mathrm{BBA}$ and $\mathrm{KBA}$ in $\mathrm{SCHH}$ following exposure to
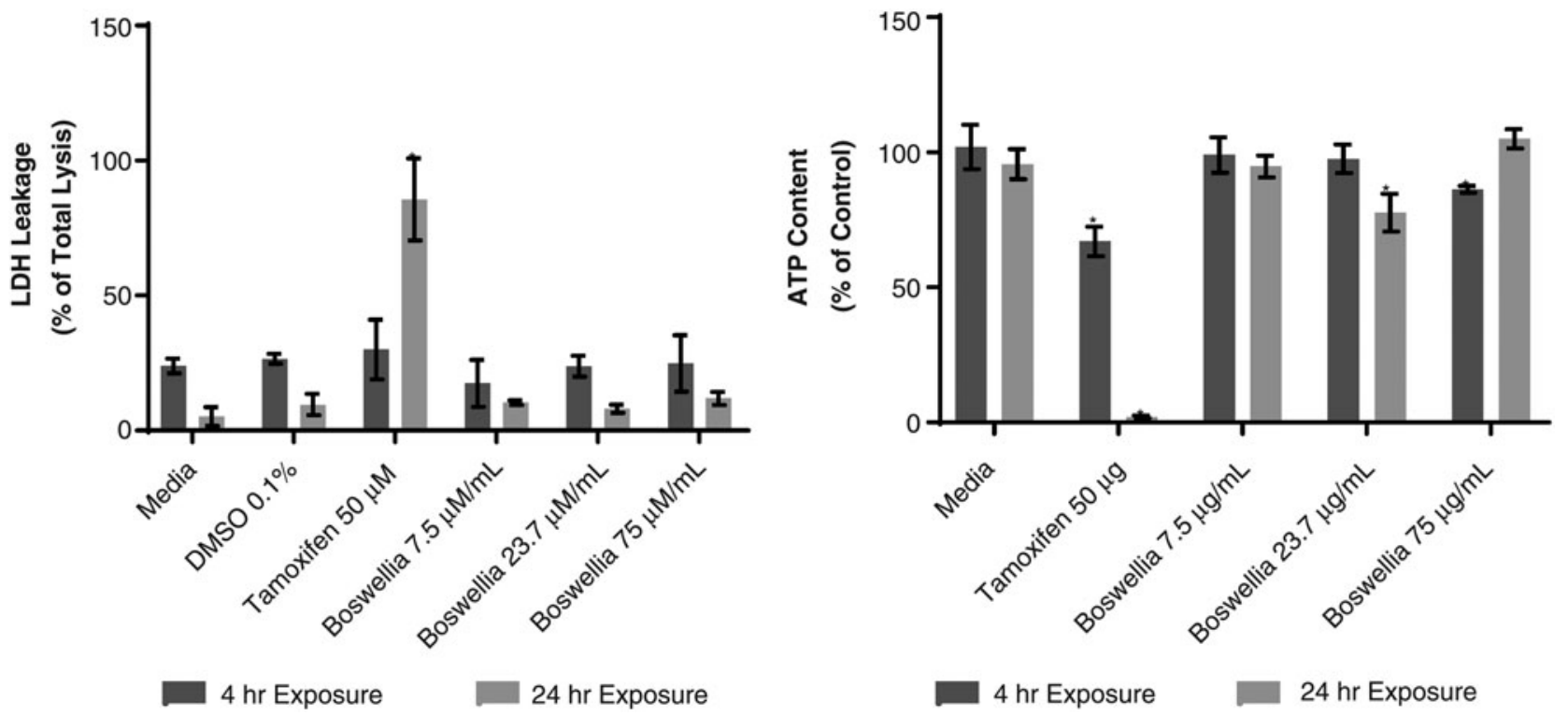

FIG. 2. LDH and ATP cytotoxicity assessment of BSE in SCHH. ATP, adenosine triphosphate; BSE, Boswellia serrata extract; LDH, lactate dehydrogenase; SCHH, sandwich-cultured human hepatocytes. 


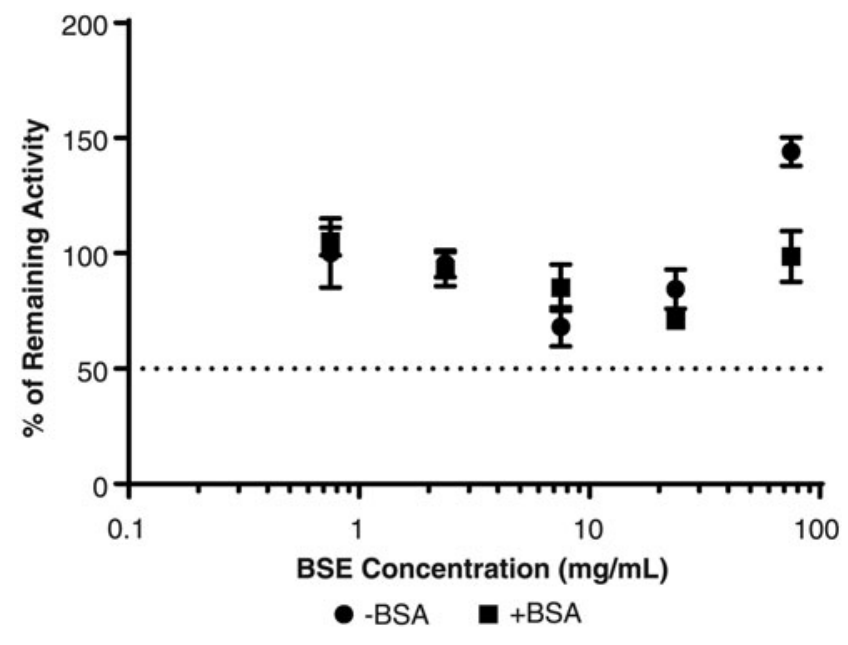

FIG. 3. CYP2C9 inhibition assessment of BSE in SCHH. Estimated $\mathrm{IC}_{50}$ value for CYP2C9 was $>75 \mu \mathrm{g} / \mathrm{mL}$ either with or without BSA added to incubations.

$\operatorname{BSE}(0.75,2.37,7.59,23.7$, and $75 \mu \mathrm{g} / \mathrm{mL})$ in the presence of $4 \%$ BSA for 0.5 hours. The ICC of BBA and KBA was shown to increase in an exposure-proportional manner in BSE-treated SCHH, in concentrations ranging from 9.90 to $507 \mu \mathrm{M}$ and 1.65 to $134 \mu \mathrm{M}$, respectively (Table 4). ICC of
BBA and KBA was $>16$-fold and $>19$-fold greater than the total exposure applied, suggesting that both BBA and KBA have high hepatic accumulation potential. In addition, these data showed that BBA had greater accumulation potential than KBA ( 3.78-fold and 6.13-fold greater) in human hepatocytes following a 30-minute exposure period.

\section{Discussion}

Liver microsomes are a useful tool for early tier screening studies, for assessing BDI potential when no information is available on the inhibition profile of a botanical extract. However, microsomal studies may overestimate the level of interaction potential since this in vitro system lacks the full complement of metabolic enzyme (e.g., Phase II) and transporter functions. More physiologically relevant in vitro models like hepatocytes, especially primary $\mathrm{SCHH}$, may be more useful for predicting clinically relevant CYP450 interactions due to the presence of fully functioning uptake and efflux transporters, and the full expression of metabolizing enzymes. Thus, we chose to study the potential for BSE to inhibit CYP2C9 and CYP3A4/5 in SCHH, and to compare results to similar incubations in PHLM and previously reported data in the literature using baculovirus-infected insect cells. ${ }^{18}$

The $\mathrm{IC}_{50}$ values generated from the PHLM studies conducted herein for BSE inhibition of CYP2C9 and CYP3A4/ 5 (11 and $1.4 \mu \mathrm{g} / \mathrm{mL}$, respectively) were remarkably similar

Table 3. Inhibition of CYP450 Enzymes in Sandwich-Cultured Human Hepatocytes with Positive Control Inhibitors

CYP2C9 inhibition positive control (no BSA)

\begin{tabular}{|c|c|c|c|c|}
\hline Treatment & $\begin{array}{c}\text { Concentration } \\
(\mu M)\end{array}$ & $\begin{array}{l}C Y P 2 C 9 \text { mean } \% \\
\text { remaining activity }\end{array}$ & $C Y P 2 C 9 S D$ & $\begin{array}{l}\text { Estimated } \\
I C_{50}(\mu M)\end{array}$ \\
\hline DMS0 & 0.00 & 100 & 9.1 & 56.2 \\
\hline Fluconazole & 5.00 & 71.1 & 1.7 & \\
\hline Fluconazole & 100 & 32.0 & 9.4 & \\
\hline \multicolumn{5}{|c|}{ CYP2C9 inhibition positive control ( $4 \%$ BSA) } \\
\hline Treatment & $\begin{array}{c}\text { Concentration } \\
(\mu M)\end{array}$ & $\begin{array}{l}C Y P 2 C 9 \text { mean } \% \\
\text { remaining activity }\end{array}$ & $C Y P 2 C 9 S D$ & $\begin{array}{l}\text { Estimated } \\
I C_{50}(\mu M)\end{array}$ \\
\hline DMS0 & 0.00 & 100 & 13 & 27.1 \\
\hline Fluconazole & 5.00 & 60.1 & 6.5 & \\
\hline Fluconazole & 100 & 16.8 & 0.80 & \\
\hline
\end{tabular}

CYP3A4 inhibition positive control (No BSA)

\begin{tabular}{lcccc}
\hline Treatment & $\begin{array}{c}\text { Concentration } \\
(\mu M)\end{array}$ & $\begin{array}{c}\text { CYP3A4/5 mean } \% \\
\text { remaining activity }\end{array}$ & CYP3A4 SD & $\begin{array}{c}\text { Estimated } \\
I C_{50}(\mu M)\end{array}$ \\
\hline DMS0 & 0 & 100 & 16 & 0.0455 \\
Ketoconazole & 0.0500 & 45.1 & 3.6 & \\
Ketoconazole & 0.250 & 24.4 & 0.20 & \\
\hline
\end{tabular}

CYP3A4 inhibition positive control (4\% BSA)

\begin{tabular}{lcccc}
\hline Treatment & $\begin{array}{c}\text { Concentration } \\
(\mu M)\end{array}$ & $\begin{array}{c}\text { CYP3A4/5 mean } \% \\
\text { remaining activity }\end{array}$ & CYP3A4 SD & $\begin{array}{r}\text { Estimated } \\
I C_{50}(\mu M)\end{array}$ \\
\hline DMS0 & 0 & 100 & 26 & 0.117 \\
Ketoconazole & 0.0500 & 54.6 & 9.1 & \\
Ketoconazole & 0.250 & 40.8 & 13 & \\
\hline
\end{tabular}

BSA, bovine serum albumin; SD, standard deviation. 


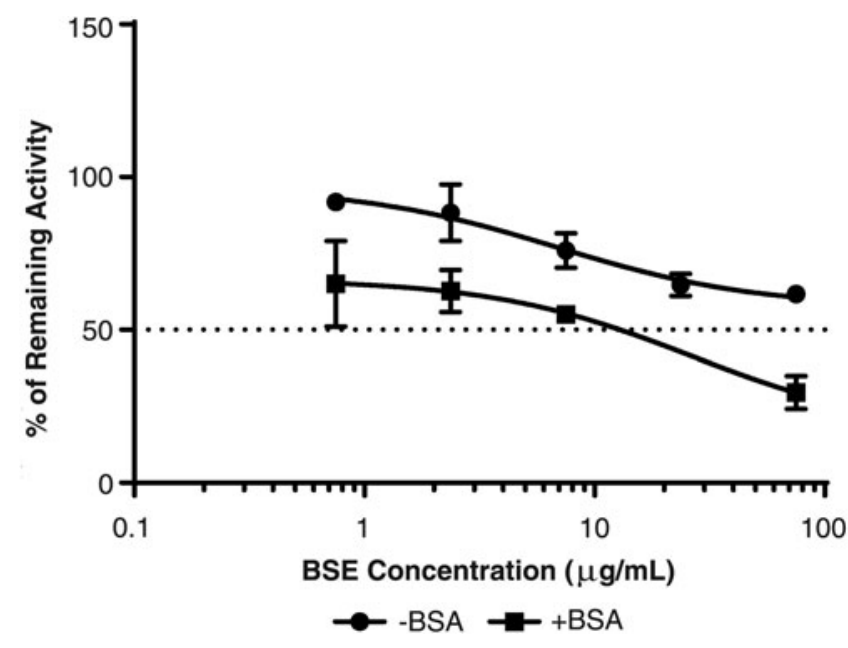

FIG. 4. CYP3A4/5 inhibition assessment of BSE in $\mathrm{SCHH}$. Estimated $\mathrm{IC}_{50}$ values for $\mathrm{CYP} 3 \mathrm{~A} 4 / 5$ were $>75 \mu \mathrm{g} / \mathrm{mL}(-\mathrm{BSA})$ and $17.4 \mu \mathrm{g} / \mathrm{mL}(+\mathrm{BSA})$.

to $\mathrm{IC}_{50}$ values generated in baculovirus-infected insect cells $\left(<10 \mu \mathrm{g} / \mathrm{mL}\right.$ CYP2C9 and CYP3A4/5). ${ }^{18}$ These same authors generated $\mathrm{IC}_{50}$ values for inhibition of CYP450 enzymes by the major boswellic acids present in Boswellia spp. In the studies of Frank and Unger, two of the most potent boswellic acids, BBA and $\mathrm{KBA}$, inhibited $\mathrm{CYP} 2 \mathrm{C} 9$ with $\mathrm{IC}_{50}$ values of 5.4 and $6.7 \mu \mathrm{M}$, respectively. Similarly, CYP3A4 was inhibited by $\mathrm{BBA}$ and $\mathrm{KBA}$ with $\mathrm{IC}_{50}$ values of 6.3 and $6.5 \mu \mathrm{M}$, respectively. The BSE used in our studies contained both $\mathrm{BBA}$ and $\mathrm{KBA}$ and were among the most prevalent boswellic acids. In fact, the levels of BBA in our BSE were over twice as much as the BSE used by Frank and Unger (19.3\% vs. $8.8 \%)$; our BSE contained slightly higher KBA as well $(4.7 \%$ vs. $3.0 \%)$. Despite these variations in boswellic acid content of extracts evaluated, the previously published results and data from our current study would leave one to conclude that BSE is a direct and potent inhibitor of CYP2C9 and CYP3A4/5 using baculovirus-infected insect cells and PHLM.

The lack of a full complement of drug-metabolizing enzymes and absence of all drug transporter function in simplistic in vitro metabolic systems, such as those previously described, can greatly alter pharmacokinetic drug/xenobiotic profiles. To assess the accuracy of the microsomal predicted clinically relevant BDI from BSE exposure, we utilized an $\mathrm{SCHH}$ system with certified functional hepatic uptake and canalicular efflux transporter protein capabilities (i.e., Transporter-Certified ${ }^{\mathrm{TM}}$ human hepatocytes), which theoretically should produce physiologically relevant ICC. Our laboratory has recently shown that this model is particularly suited for studying clearance interactions with complex botanical mixtures. ${ }^{22} \mathrm{We}$ demonstrated that an intrinsic clearance approach using the Transporter-Certified human hepatocytes to study BDI with Schisandra spp. and St. John's work provided remarkably consistent results with in vivo data from human clinical studies.

BSE inhibition of CYP2C9 in $\mathrm{SCHH}$ was significantly less potent $\left(\mathrm{IC}_{50}>75 \mu \mathrm{g} / \mathrm{mL}\right)$ than what was observed in PHLM $\left(\mathrm{IC}_{50} 11 \mu \mathrm{g} / \mathrm{mL}\right)$, regardless of whether BSA was added to incubations. Similar results for BSE potential to inhibit CYP3A4 using SCHH were observed when BSA was not added to incubations $(>75 \mu \mathrm{g} / \mathrm{mL})$; however, with the addition of $\mathrm{BSA}$, the $\mathrm{IC}_{50}$ value for CYP3A4 decreased to $17.4 \mu \mathrm{g} / \mathrm{mL}$. This $\mathrm{IC}_{50}$ value for $\mathrm{BSE}$ was still $>10$-fold greater than observed in PHLM $(1.4 \mu \mathrm{g} / \mathrm{mL})$ incubations.

Both BBA and KBA (and likely the other boswellic acids) are reported to be highly protein bound $\geq 95 \%$. ${ }^{1}$ The addition of BSA likely helped to solubilize BSE constituents, resulting in the observed inhibition of CYP3A4 with BSA. Solubility with complex botanical extracts may be less of a factor in microsomal studies, particularly with the lower test concentrations used. The lack of inhibition of CYP2C9 by BSE observed in $\mathrm{SCHH}$, regardless of whether BSA was present, may be related to the use of ibuprofen as substrate. The $\mathrm{Km}$ for ibuprofen as a substrate for CYP2C9 is quite high, suggesting ibuprofen is a less sensitive substrate than diclofenac, which was used in the PHLM studies. ${ }^{30}$

The obvious question related to inhibition data generated from any in vitro system is how these results may translate to clinically meaningful changes in the pharmacokinetics of drugs. In addition, the relevance of in vitro test concentrations of botanical extracts and associated phytochemical constituents are questioned, including consideration of oral absorption of phytochemicals and the physiological relevance of in vitro incubation conditions. An additional advantage of the hepatic model used in these studies is that novel proprietary technology, B-CLEAR, allows for characterization of hepatobiliary

Table 4. Intracellular Concentrations of $\beta$-Boswellic Acid and 11-Keto- $\beta$-Boswellic Acid in Sandwich-Cultured Human Hepatocytes

\begin{tabular}{|c|c|c|c|c|c|c|}
\hline $\begin{array}{l}\text { Total Boswellia } \\
\text { extract concentration } \\
\text { dosed }(\mu g / m L)\end{array}$ & $\begin{array}{c}\text { Estimated BBA } \\
\text { concentration } \\
\text { dosed }(\mu M)^{\mathrm{a}}\end{array}$ & $\begin{array}{c}\text { Estimated keto- } B B A \\
\text { concentration } \\
\text { dosed }(\mu M)^{\mathrm{a}}\end{array}$ & $\begin{array}{l}\text { Total BBA } \\
\text { ICC }(\mu M)^{\mathrm{b}}\end{array}$ & $S D$ & $\begin{array}{l}\text { Total keto-BBA } \\
\qquad I C C(\mu M)^{\mathrm{b}}\end{array}$ & $S D$ \\
\hline 0.750 & 0.317 & 0.0682 & 9.90 & 2.4 & 1.65 & 0.50 \\
\hline 2.37 & 1.00 & 0.215 & 26.4 & 3.0 & 4.31 & 0.75 \\
\hline 7.50 & 3.17 & 0.682 & 70.7 & 21 & 13.2 & 3.6 \\
\hline 23.7 & 10.0 & 2.15 & 184 & 19 & 42.2 & 5.2 \\
\hline 75.0 & 31.7 & 6.82 & 507 & 200 & 134 & 53 \\
\hline
\end{tabular}

aEstimate of BSE constituent concentration in culture media at time " 0 ." Estimate derived from supplier's Certificate of Analysis results indicating percentage of constituent per gram of total extract and volume of culture media.

${ }^{\mathrm{b}} \mathrm{ICC}$ of each BSE constituent represents mass of analyte in the hepatocytes (cellular accumulation) adjusted to the hepatocyte intracellular fluid volume of $7.69 \mu \mathrm{L} / \mathrm{mg}$ protein. ICC was determined following conclusion of exposure period.

ICC, intracellular concentration. 
disposition of compounds generating ICC of phytochemical constituents such as BBA and KBA. ${ }^{20-22,26-28}$

As shown in Table 4, ICC of both BBA and KBA increased in an exposure-proportional manner across the range of BSE exposures tested. Employing the basic inhibition $[I] / K_{i}$ model assuming competitive inhibition and using the Cheng-Prusoff equation to estimate $K_{i}$ from $\mathrm{IC}_{50}$ estimates, where the ICC of BBA or KBA observed in the SCHH is substituted for $[I]$ and the $\mathrm{IC}_{50}$ values reported for CYP2C9 (BBA: $5.4 \mu \mathrm{M}$ and KBA: $6.7 \mu \mathrm{M}$ ) and CYP3A4 (BBA: $6.3 \mu \mathrm{M}$ and KBA: $6.5 \mu \mathrm{M})$ are utilized, significant inhibition $\left([I] / K_{i}>1\right)$ of CYP2C9 and CYP3A4 would be predicted at our lowest exposure of BSE tested $(0.75 \mu \mathrm{g} / \mathrm{mL})$ from a BBA interaction (Table 5).

Furthermore, quite extensive inhibition of both isoforms would be expected at higher exposures of BSE (Table 5). Interestingly, only CYP3A4 inhibition was observed with the addition of BSA, resulting in an $\mathrm{IC}_{50}$ value of $17.4 \mu \mathrm{g} / \mathrm{mL}$ BSE, which would correspond to total exposure of $\sim 7.3 \mu \mathrm{M}$ BBA and $\sim 1.6 \mu \mathrm{M} \mathrm{KBA}$. At this BSE exposure level, total ICC of BBA ( $\sim 129 \mu \mathrm{M}$ total; Fig. 5) and KBA $(\sim 31.5 \mu \mathrm{M}$ total; Fig. 6) was $\sim 20$ - and $\sim 4$-fold greater than reported $\mathrm{IC}_{50}$ values from the published scientific literature for CYP3A4 inhibition by BBA and KBA, respectively. ${ }^{18}$

Evaluation of ICC of BBA and KBA across multiple BSE exposures allowed us to evaluate the concentration of these constituents at the level of the enzyme, while correlating to total exposure applied to the outside of the hepatocyte. When you consider $95 \%$ protein binding of boswellic acids and apply the basic inhibition model using fraction unbound ICC, $[I] / K_{i}$ drops from 41.0 to 2.05 for BBA and 9.69 to 0.485 for KBA (Table 5). These revised [ []$/ K_{i}$ values still suggested CYP3A4 inhibition was likely for BBA and possible for KBA,

Table 5. Risk Prediction of Drug Metabolism INHIBITION BY BOSWELLIA SERRATA EXTRACT EXPOSURE

\begin{tabular}{|c|c|c|c|c|c|}
\hline $\begin{array}{l}B S E \\
(\mu g / m L)\end{array}$ & $\begin{array}{l}\text { Boswellic } \\
\text { acid }\end{array}$ & $\begin{array}{c}\text { CYP2C9 } \\
{[I] / \mathrm{K}_{\mathrm{i}}} \\
\text { ratio }^{\mathrm{a}}\end{array}$ & $\begin{array}{c}\text { CYP2C9 } \\
{\left[I_{\text {ful }} / \mathrm{K}_{\mathrm{i}}\right.} \\
\text { ratio }^{\mathrm{a}}\end{array}$ & $\begin{array}{c}\text { CYP3A4 } \\
{[I] / \mathrm{K}_{\mathrm{i}}} \\
\text { ratio }^{\mathrm{a}}\end{array}$ & $\begin{array}{c}\text { CYP3A4 } \\
{\left[I_{\text {fuu }}\right] / \mathrm{K}_{\mathrm{i}}} \\
\text { ratio }^{\mathrm{b}}\end{array}$ \\
\hline 0.75 & $\begin{array}{l}\text { BBA } \\
\text { KBA }\end{array}$ & $\begin{array}{l}3.67 \\
0.49\end{array}$ & $\begin{array}{l}0.18 \\
0.02\end{array}$ & $\begin{array}{l}3.14 \\
0.51\end{array}$ & $\begin{array}{l}0.16 \\
0.03\end{array}$ \\
\hline 2.37 & $\begin{array}{l}\text { BBA } \\
\text { KBA }\end{array}$ & $\begin{array}{l}9.78 \\
1.29\end{array}$ & $\begin{array}{l}0.49 \\
0.06\end{array}$ & $\begin{array}{l}8.38 \\
1.33\end{array}$ & $\begin{array}{l}0.42 \\
0.07\end{array}$ \\
\hline 7.5 & $\begin{array}{l}\text { BBA } \\
\text { KBA }\end{array}$ & $\begin{array}{l}26.2 \\
3.94\end{array}$ & $\begin{array}{l}1.31 \\
0.20\end{array}$ & $\begin{array}{l}22.4 \\
4.06\end{array}$ & $\begin{array}{l}1.12 \\
0.20\end{array}$ \\
\hline $17.4^{\mathrm{c}}$ & $\begin{array}{l}\text { BBA } \\
\text { KBA }\end{array}$ & - & - & $\begin{array}{l}41.0 \\
9.69\end{array}$ & $\begin{array}{l}2.05 \\
0.49\end{array}$ \\
\hline 23.7 & $\begin{array}{l}\text { BBA } \\
\text { KBA }\end{array}$ & $\begin{array}{l}68.1 \\
12.6\end{array}$ & $\begin{array}{l}3.41 \\
0.63\end{array}$ & $\begin{array}{l}58.4 \\
13.0\end{array}$ & $\begin{array}{l}2.92 \\
0.65\end{array}$ \\
\hline 75 & $\begin{array}{l}\text { BBA } \\
\text { KBA }\end{array}$ & $\begin{array}{r}188.0 \\
40.0\end{array}$ & $\begin{array}{l}9.39 \\
2.00\end{array}$ & $\begin{array}{r}161.0 \\
41.2\end{array}$ & $\begin{array}{l}8.05 \\
2.06\end{array}$ \\
\hline
\end{tabular}

${ }^{\mathrm{a}}$ Basic inhibition model as described by Bjornsson et al. ${ }^{32}$ where likely interaction $=[I] / K_{i}>1$, possible interaction $=1>[I] / K_{i}>0.1$, and remote interaction $=[I] / K_{i}<0.1^{32}$; ICC of BBA and KBA was substituted for $[I](\mathrm{Cmax})$ and $\mathrm{IC}_{50}$ values for individual boswellic acids were taken from Frank and Unger. ${ }^{18}$

${ }^{\mathrm{b}}$ Applied reported protein binding of boswellic acids to BBA and KBA ICC for calculation of fraction unbound ICC (fu) and then applied basic inhibition model. ${ }^{1}$

${ }^{c}$ Applied estimated ICC of BBA and KBA from estimated BSE $\mathrm{IC}_{50}$ value for CYP3A4 to basic inhibition model.

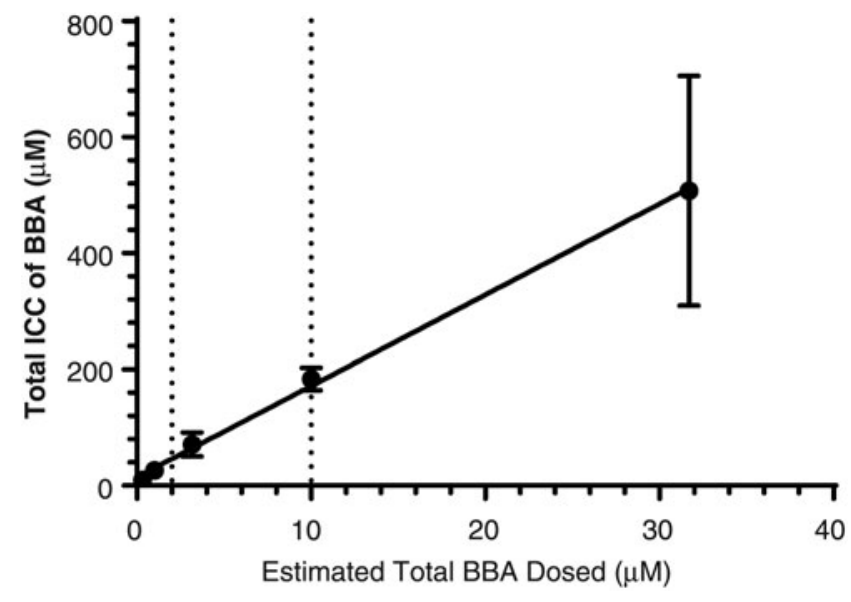

FIG. 5. ICC of BBA in SCHH following exposure to BSE (vertical dotted lines from $X$-axis represent reported plasma Cmax values; $\left.Y=15.67 \times X+14.8 ; R^{2}=0.998\right)$. BBA, $\beta$ boswellic acid; ICC, intracellular concentration.

but may explain why the inhibition observed was not as efficacious. Application of protein binding on ICC had a similar impact on $[I] / K_{i}$ values for CYP2C9. Evaluation of this correlation suggested plasma concentrations of BBA and KBA observed in human clinical trials would likely achieve hepatic ICC greater than $\mathrm{IC}_{50}$ values determined in in vitro models.

Human plasma concentrations of boswellic acids, including BBA and KBA, are greatly enhanced when BSE is given with food, particularly high-fat diets. ${ }^{4,5}$ As shown in Table 1 and discussed below, levels of both BBA and KBA measured in human plasma correspond to ICC of both phytochemicals observed at the lower range of exposures of BSE tested in SCHH (Table 1). However, these exposures of BSE did not correspond to inhibition of CYP2C9 or CYP3A4 inhibition in $\mathrm{SCHH}$.

In a randomized, double-blind, placebo-controlled trial to determine tolerability and efficacy of orally administered

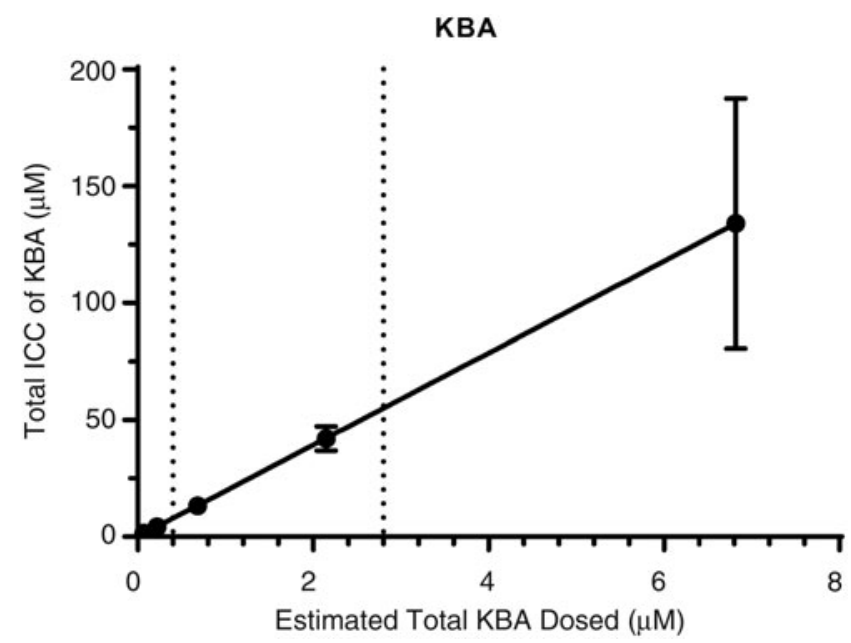

FIG. 6. ICC of KBA in SCHH following exposure to BSE (vertical dotted lines from $X$-axis represent reported plasma Cmax values; $Y=19.65 \times X+0.02313 ; R^{2}=1$ ). KBA, 11 keto- $\beta$-boswellic acid. 
BSE (designated PS0201Bo) in patients with Crohn's disease, patients received a total daily exposure of $2400 \mathrm{mg}$ ( $800 \mathrm{mg}$ BSE, three times per day). The BSE was taken with meals for a period of 52 weeks. Steady-state concentrations of $\mathrm{BBA}$ and $\mathrm{KBA}$ reported from this study were $6.35 \pm 1.0 \mu \mathrm{M}$ and $0.33 \pm 0.1 \mu \mathrm{M}$, respectively. ${ }^{8}$ In a pilot human clinical trial that also used $4200 \mathrm{mg} /$ day BSE for 4 weeks, an average concentration of $0.1379 \mu \mathrm{M}$ KBA was measured in plasma; BBA was not measured in this study. ${ }^{6}$ Büchele and Simmet reported plasma levels of both BBA and $\mathrm{KBA}$ of 10.1 and $0.34 \mu \mathrm{M}$ in a single patient, who had taken $3144 \mathrm{mg}$ BSE per day for 10 days. ${ }^{7}$ Abdel-Tawab et al. reported plasma levels of $1.9 \mu \mathrm{M}$ KBA after a single oral exposure of BSE of $1600 \mathrm{mg} .{ }^{31}$ However, it should be noted that this was an analytical method development paper and data represent only a single individual.

Finally, in an open-label, uncontrolled pharmacokinetic trial with 12 healthy subjects, a single exposure of $333 \mathrm{mg}$ BSE was given with food and KBA plasma levels were measured. $^{3}$ Despite the lower exposure used in this clinical trial compared to other studies previously mentioned, a Cmax of $2.72 \mu \mathrm{M}$ of KBA was measured at 4.5 hours (Tmax) after oral consumption of BSE. Interestingly, the BSE used in this study (Drug Wok Vel ${ }^{\mathrm{TM}}$ ) contained similar levels of BBA (18.51\%) and KBA (6.44\%) as the BSE used in our in vitro studies $(19.3 \% \mathrm{BBA}$ and $4.66 \% \mathrm{KBA})$.

The human plasma levels for boswellic acids reported in the literature support the relevancy of the test concentrations used and ICC observed in our in vitro SCHH studies, and allow us to make predictions on the likelihood of clinically relevant BDI based on our in vitro results. Generally, recommended dosages for asthma, osteoarthritis, rheumatoid arthritis, and ulcerative colitis are at or below $400 \mathrm{mg}$ per dose, but often recommended to take up to three times daily (based on a survey of BSE-containing products in the marketplace). ${ }^{13}$ Although the majority of clinical studies used BSE dose levels twofold and fourfold higher than what is typically recommended as a dietary supplement, plasma levels of boswellic acids are clearly achievable at lower exposures as evidenced by the Drug Wok Vel product. $^{3}$

Drug interactions are of particular concern with narrow therapeutic index drugs since even small increases in blood concentrations of these drugs can precipitate serious adverse events. Two separate cases of an interaction between BSE and the anticoagulant warfarin have been reported in the literature where both patients experienced international normalized ratio (INR) elevations, putting them at risk for serious and potentially fatal bleeds. ${ }^{33}$ The two patients were taking BSE as a single herb product at doses of 1200 and $1500 \mathrm{mg} /$ day. Upon withdrawal of BSE, INR returned to baseline and the patients made a full recovery. Warfarin is a narrow therapeutic index drug and small changes in blood concentrations may increase a patient's risk of either clots or bleeding. The majority of warfarin is metabolized by CYP2C9, although CYP1A2/3A4/2C19 metabolism occurs to a lesser extent. In light of our results, it is possible that CYP3A4 inhibition of BSE contributed to the reported INR increases in the case reports.

Our interest in assessing the BDI risk associated with BSE-containing dietary supplements was based on previous in vitro data published in the literature, the increasing popu- larity of this botanical in the marketplace, and its potential to be used as adjunctive therapy to NSAIDs. We focused our work on CYP2C9 and CYP3A4 since previous studies indicated that these isoforms were inhibited by BSE, and both are important in the metabolism of NSAIDs such as ibuprofen. In addition, older adults ( $>65$ years) are the top users of dietary supplements, NSAIDs, and prescription medications. ${ }^{15,16,34}$ In fact, the prevalence of NSAID use in patients older than 65 is as high as $96 \%$ in the general practice setting. ${ }^{34}$ Thus, we speculated that the elderly population might be particularly at risk for BDI associated with BSE. However, based on the data generated in this study using SCHH to monitor inhibition of CYP2C9 and CYP3A4, we would conclude that BSE is unlikely to cause interactions with NSAIDs such as ibuprofen at recommended dietary supplement exposure levels. This conclusion is in agreement with a seemingly safe history of use of BSE-containing dietary supplements.

There are limitations associated with this study that could affect the overall BDI potential associated with BSE. First, even when data are available for the major boswellic acids found in BSE to allow comparisons across studies, there may be other phytochemical constituents that play a role in metabolic inhibition. In fact, Frank and Unger also tested in their in vitro studies, a related Boswellia sp. gum resin (Boswellia frereana) that was devoid of the major boswellic acids, and yet showed comparable inhibition across CYP enzymes. The authors concluded that there were additional CYP inhibitory phytoconstituents present in Boswellia spp. ${ }^{18}$

In addition, we did not evaluate the ability of BSE to induce CYP450 enzymes, nor did we measure the effect of $\mathrm{BSE}$ on in vitro clearance of a clinically relevant drug substrate. In our previous work, we demonstrated that an in vitro clearance BDI approach could accurately predict in vivo BDI. ${ }^{22}$ We showed that studying in vitro clearance predicted both the BDI effect (e.g., inhibition or induction) and relative strength of the BDI effect (\% deviation from normal). This mechanistic approach could delineate all BDI mechanisms that may be involved in altering the pharmacokinetics of a victim drug.

Finally, we evaluated the ICC of BBA and KBA in the presence of BSA. An evaluation of the ICC of boswellic acids in the absence of protein may help better understand the protein affect observed in the CYP3A4 inhibition data.

\section{Conclusion}

The potent CYP450 inhibition capability of BSE observed in microsomal systems was not observed in more physiologically relevant whole-cell hepatocyte models such as SCHH. $\mathrm{SCHH}$ have a number of advantages, including uptake and efflux transporters, the full range of metabolizing enzymes, and the regulatory machinery that controls these processes, which make them particularly useful for studying complex mixtures such as botanicals. Although our data would suggest that BDI with BSE is low for most drugs, narrow therapeutic drugs such as warfarin and other sensitive substrates for CYP2C9 (e.g., diclofenac) should still be used with caution when combined with BSE. Even though ibuprofen may be a less sensitive CYP2C9 substrate, the ICC of BBA and $\mathrm{KBA}$ observed in the SCHH was high enough to possibly inhibit diclofenac, an NSAID that is still used in certain 
geographies. In addition, if novel absorption-enhancing formulations are developed for BSE that may dramatically increase systemic tissue distribution of boswellic acids and/or other phytochemical constituents, reevaluation of BDI should be conducted. ${ }^{35}$

\section{Acknowledgment}

The authors would like to thank Brittany Hayslip for editorial assistance in developing this article.

\section{Author Disclosure Statement}

A.L.R., J.M.P., L.L., and H.D. are employees of The Procter and Gamble Company, which funded this work. K.M.F., W.W.F., A.G.H., C.B.B., K.R.B., and J.P.J. are employees of BioIVT, where the majority of work was conducted.

\section{References}

1. Abdel-Tawab M, Werz O, Schubert-Zsilavecz M. Boswellia serrata: an overall assessment of in vitro, preclinical, pharmokinetic and clinical data. Clin Pharmacokinet 2011:50; 349-369.

2. Ammon HPT. Boswellic acids and their role in chronic inflammatory diseases. In: Anti-Inflammatory Nutraceuticals and Chronic Diseases, Advances in Experimental Medicine and Biology, Volume 928. SC Gupta, S Prasad, BB Aggarwal (eds); pp. 291-327. Switzerland: Springer International Publishing; 2016.

3. Sharma S, Thawani V, Hingorani L, et al. Pharmacokinetic study of 11-keto $\beta$-boswellic acid. Phytomedicine 2004:11; 255-260.

4. Sterk V, Büchele B, Simmet T. Effect of food intake on the bioavailability of boswellic acids from a herbal preparation in healthy volunteers. Planta Med 2004:70;1155-1160.

5. Skarke C, Kuczka K, Tausch L, et al. Increased bioavailability of 11-keto- $\beta$-boswellic acid following single oral exposure frankincense extract administration after a standardized meal in healthy male volunteers: modeling and simulation considerations for evaluating drug exposures. J Clin Pharmacol 2012:52;1592-1600.

6. Kirste S, Treier M, Wehrle SJ, et al. Boswellia serrata acts on cerebral edema in patients irradiated for brain tumors. Cancer 2011:117;3788-3795.

7. Büchele B, Simmet T. Analysis of 12 different pentacyclic triterpenic acids from frankincense in human plasma by high-performance liquid chromatography and photodiode array detection. J Chromatogr B 2003:795:355-362.

8. Tausch L, Henkel A, Siemoneit U, et al. Identification of human cathepsin $\mathrm{G}$ as a functional target of boswellic acids from the anti-inflammatory remedy frankincense. J Immunol 2009:183;3433-3442.

9. Shah SA, Rathod IS, Suhagia BN, et al. Estimation of boswellic acids from market formulations of Boswellia serrata extract and 11-keto $\beta$-boswellic acid in human plasma by high-performance thin-layer chromatography. J Chromatogr B 2007:848;232-238.

10. Kantor ED, Rehm CD, Du M, et al. Trends in dietary supplement use among US adults from 1999-2012. JAMA 2016: 316;1464-1474.

11. Smith T, Kawa K, Eckl V, et al. Herbal supplement sales in US increase $8.5 \%$ in 2017, topping $\$ 8$ billion. HerbalGram 2018:119;62-71.
12. Smith T, Lynch ME, Johnson J, et al. Herbal dietary supplement sales in US increase $6.8 \%$ in 2014. HerbalGram 2015: 107;52-59.

13. National Institutes of Health, NIH 2018. Dietary Supplement Label Database: Products that contain Boswellia serrata. Bethesda, MD. https://www.dsld.nlm.nih.gov/dsld/ rptQSearch.jsp?item=boswellia+serrata\&db=adsld (last accessed October 3, 2018).

14. Roumie CL, Griffin MR. Over-the-counter analgesics in older adults: a call for improved labelling and consumer education. Drugs Aging 2004:21;485-498.

15. National Center for Health Statistics. Health, United States, 2014: With Special Feature on Adults Aged 55-64. Hyattsville, MD: National Center for Health Statistics (US); 2015

16. Council for Responsible Nutrition, CRN 2017. Annual survey on dietary supplements. Council for Responsible Nutrition, Washington, DC. www.crn.org/survey (last accessed November 5, 2018).

17. Agbabiaka T, Wider B, Waston L, et al. Concurrent use of prescription drugs and herbal medicinal products in older adults: a systemic review. Drug Aging 2017:34;891-905.

18. Frank A, Unger M. Analysis of frankincense from various Boswellia species with inhibitory activity on human drug metabolizing cytochrome P450 enzymes using liquid chromatography mass spectrometry after automated on-line extraction. J Chromatogr A 2006:1112;255-262.

19. Hewitt NJ, Lechón MJG, Houston JB, et al. Primary hepatocytes: current understanding of the regulation of metabolic enzymes and transporter proteins, and pharmaceutical practice for the use of hepatocytes in metabolism, enzyme induction, transporter, clearance, and hepatotoxicity studies. Drug Metab Rev 2007:39;159-234.

20. Ghibellini G, Vasist LS, Leslie EM, et al. In vitro-in vivo correlation of hepatobiliary drug clearance in humans. Clin Pharmacol Ther 2007:81;406-413.

21. Jackson JP, Kabirov KK, Kapetanovic IM, et al. In vitro assessment of P450 induction potential of novel chemopreventive agents SR13668, 9-cis-UAB30, and pentamethychromanol in primary cultures of human hepatocytes. Chem Biol Interact 2009:179;263-272.

22. Jackson JP, Freeman KM, Friley WW, et al. Prediction of clinically relevant herb-drug clearance interactions using sandwich-cultured human hepatocytes: Schisandra spp. case study. Drug Metab Dispos 2017:45;1019-1026.

23. Mazaleuskaya LL, Theken KN, Gong L, et al. PharmGKB summary: ibuprofen pathways. Pharmacogenet Genomics 2015:25;96-106.

24. Pearce RE, McIntyre CJ, Madan A, et al. Effects of freezing, thawing, and storing human liver microsomes on cytochrome P450 activity. Arch Biochem Biophys 1996:331;145-169.

25. Parkinson A, Mudra DR, Johnson C, et al. The effects of gender, age, ethnicity and liver cirrhosis on cytochrome P450 enzyme activity in human liver microsomes and inducibility in cultured human hepatocytes. Toxicol Appl Pharmacol 2004:199;193-209.

26. Chandra P, Brouwer KL. The complexities of hepatic drug transport: current knowledge and emerging concepts. Pharm Res 2004:21:719-735.

27. Liu X, Chism JP, LeCluyse EL, et al. Correlation of biliary excretion in sandwich-cultured rat hepatocytes and in vivo in rats. Drug Metab Dispos 1999:27;637-644.

28. Marion TL, Perry CH, St Claire RL, et al. Endogenous bile acid disposition in rat and human sandwich-cultured hepatocytes. Toxicol Appl Pharmacol 2012:261;1-9. 
29. Lee JK, Brouwer KR. Determination of intracellular volume of rat and human sandwich-cultured hepatocytes (Abstract). Toxicol Sci 2010:114;339.

30. Hamman MA, Thompson GA, Hall, SD. Regioselective and stereoselective metabolism of ibuprofen by human cytochrome P450 2C. Biochem Pharmacol 1997:54;33-41.

31. Abdel-Tawab M, Kaunzinger A, Bahr U, et al. Development of a high-performance liquid chromatographic method for the determination of 11-keto- $\beta$-boswellic acid in human plasma. J Chromatogr B 2001:761;221-227.

32. Bjornsson TD, Callaghan JT, Einolf HJ, et al. The conduct of in vitro and in vivo drug-drug interaction studies: a PhRMA perspective. Drug Metab Dispos 2003:31;815-832.

33. Milić N, Milošević N, Kon SG, et al. Warfarin interactions with medicinal herbs. Nat Prod Commun 2014:9;12111216.
34. Wongrakpanich S, Wongrakpanich A, Melhado K, et al. A comprehensive review of non-steroidal anti-inflammatory drug use in the elderly. Aging Dis 2018:9;143-150.

35. Husch J, Bohnet J, Fricker G, et al. Enhanced absorption of boswellic acids by a lecithin delivery form $\left(\right.$ Phytosome $^{\circledR}$ ) of Boswellia extract. Fitoterapia 2013:84;89-98.

Address correspondence to: Dr. Amy L. Roe The Procter \& Gamble Company $M B C$, Box 2006 8700 Mason-Montgomery Road Cincinnati, OH 45040

E-mail: roe.al@pg.com 